\title{
COMBINING INSAR, LEVELLING AND GNSS FOR THE ESTIMATION OF 3D SURFACE DISPLACEMENTS
}

\author{
T. Fuhrmann ${ }^{1}$, M. Caro Cuenca ${ }^{2}$, A. Knöpfler ${ }^{1}$, F.J. van Leijen ${ }^{3}$, M. Mayer ${ }^{1}$, M. Westerhaus ${ }^{1}$, R.F. Hanssen ${ }^{3}$, and \\ B. Heck ${ }^{1}$ \\ ${ }^{1}$ Geodetic Institute, Karlsruhe Institute of Technology, Germany \\ ${ }^{2}$ Department of Radar Technology, TNO, The Netherlands \\ ${ }^{3}$ Department of Geoscience and Remote Sensing, Delft University of Technology, The Netherlands
}

\begin{abstract}
The three geodetic techniques InSAR, levelling and GNSS are complementary w.r.t. (i) the sensitivity to horizontal and vertical displacement components, (ii) the spatial and temporal resolution of the measurements and (iii) the accuracy of the resulting displacements. We present a strategy to robustly combine the displacement estimates of the three techniques with a focus on long-term, linear movements. The linear displacement rates from InSAR in ascending and descending image geometry are combined with vertical and horizontal rates from levelling and GNSS, respectively, resulting in 3D velocity vectors at a dense surface grid. The results of our combination approach indicate that it is possible to derive realistic surface movements on the sub-mm/a scale with significance.
\end{abstract}

\section{INTRODUCTION}

Having access to a large amount of geodetic data from InSAR, levelling and GNSS, our study is carried out in the tectonically interesting Upper Rhine Graben (URG) region. The URG is located in the border triangle between Germany, France and Switzerland (Fig. 1) and is the most prominent part of the European Cenozoic Rift system [1]. In recent years, the area is characterised by moderate tectonic and seismic activity, but on the other hand, carrying a significant probability for strong earthquakes [2]. As the complex fault system of the URG is capable of both extensional and strike slip faulting [3], vertical as well as horizontal surface movements are expected, albeit on a small scale $(<1 \mathrm{~mm} / \mathrm{a})$.

We use all available data sets from InSAR, precise levelling and GNSS in order to estimate linear surface motions in the URG area. In order to obtain the best possible solution for linear displacement rates from InSAR, we combine the line of sight (LOS) displacement time series of ERS and Envisat separately for ascending and descending image geometries. Ordinary Kriging is used for the interpolation of InSAR, Levelling and GNSS data

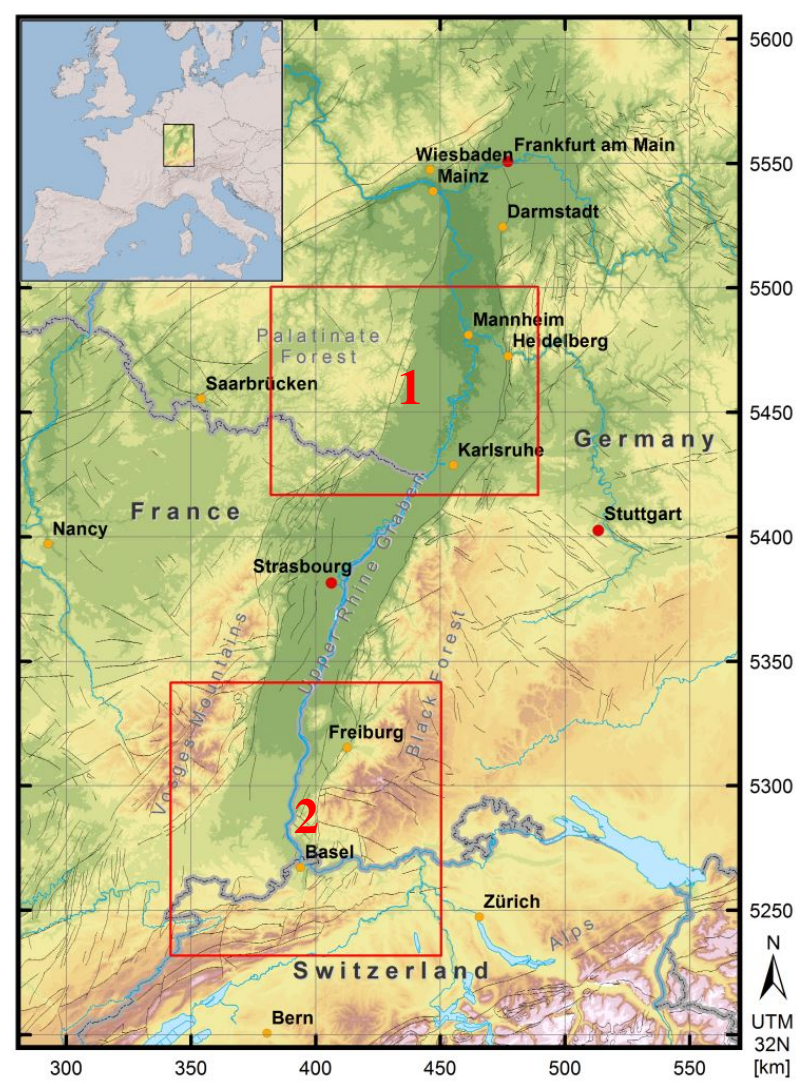

Figure 1. The Upper Rhine Graben area: DEM using SRTM-3 data and major fault lines (black, from www.onegeology.org). The two areas marked by red rectangles serve as test areas for the combination approach, 1: Northern URG, 2: Southern URG.

with a focus on the covariance model used for each technique. Our combination approach consists of two steps. First, we interpolate the LOS velocities from InSAR to the location of levelling and GNSS measurements in order to estimate an offset and a trend between InSAR and levelling and between InSAR and GNSS. Second, we interpolate the linear velocities from InSAR, levelling and GNSS to a dense grid and perform the mathematical fusion of the data. 
The paper will firstly introduce our database. Secondly, we present the strategy to robustly combine the displacement estimates using least-squares adjustment (LSA). Sect. 4 shows results for 3D displacement rates and corresponding accuracies in two test areas (red rectangles in Fig. 1).

\section{DATABASE}

The spatial and temporal distribution of data used within our combination approach is shown in Fig. 2 and Fig. 3, respectively. Information on the amount of data and the strategies applied within single-technique analyses is described in the following.

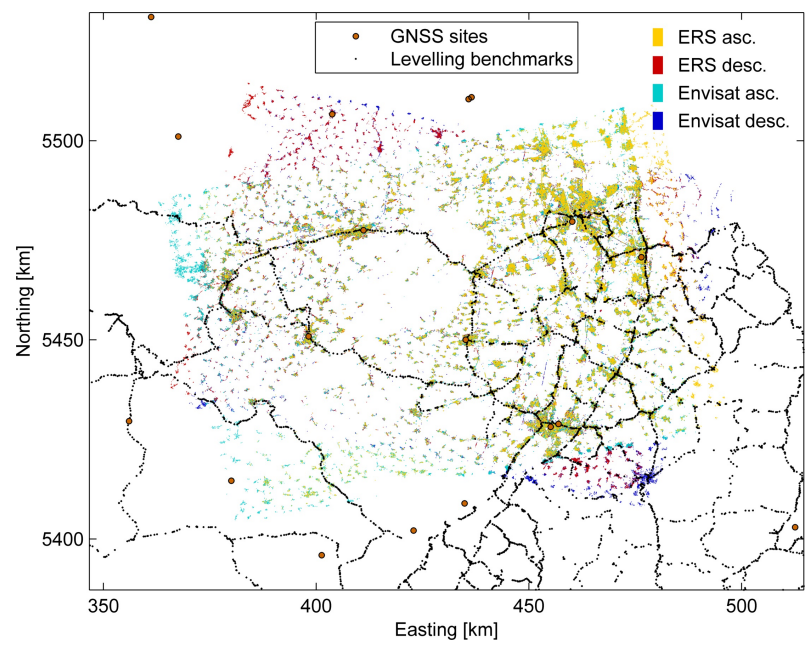

Figure 2. Spatial distribution of PS points, levelling benchmarks and GNSS sites in the northern URG. The four different stacks of SAR data (cf. Tab. 1) are displayed in different colors.

\subsection{InSAR}

SAR data acquired by ERS-1/2 and Envisat covering a period from 1992 to 2000 and 2002 to 2010, resp., both from ascending and descending tracks are analysed using the StaMPS (Stanford Method for Persistent Scatterers) software [4]. We use SAR data in two ascending and one descending tracks covering the whole URG area. The number of usable scenes is shown in Tab. 1. As more scenes are available from Envisat in the southern part of the region, we process the Envisat data of track 487 and 294 in different stacks for the northern and the southern part (cf. Tab. 1). Focussing on small displacement rates, we calculate quality indicators as described in [5] at every PS point in order to filter the resulting PS points of each analysed image stack.
Table 1. Usable SAR acquisitions in the URG area in ascending tracks 258 and 487 and descending track 294. Significantly more Envisat scenes are available in the southern part of tracks 487 and 294.

\begin{tabular}{lccc} 
Satellite & Track & Number & Period \\
\hline ERS-1/2 & 258 & 24 & $1993 / 03-2000 / 05$ \\
Envisat & 258 & 19 & $2004 / 12-2008 / 08$ \\
\hline ERS-1/2 & 487 & 23 & $1993 / 04-2000 / 06$ \\
Envisat & $487 \mathrm{~N}^{1}$ & 19 & $2003 / 07-2010 / 08$ \\
Envisat & $487 \mathrm{~S}^{1}$ & 40 & $2002 / 11-2010 / 10$ \\
\hline ERS-1/2 & 294 & 55 & $1992 / 04-2000 / 08$ \\
Envisat & $294 \mathrm{~N}^{1}$ & 18 & $2003 / 12-2008 / 12$ \\
Envisat & $294 \mathrm{~S}^{1}$ & 43 & $2003 / 12-2010 / 10$ \\
\hline
\end{tabular}

1: Northern part of the URG

2: Southern part of the URG

\subsection{Levelling}

The levelling database consists of repeatedly measured height differences along levelling lines in the URG area obtained by the surveying authorities of Germany, France and Switzerland. The lines build a network of measurements with different spatial distributions in each country. As the measurement dates of the levelling campaigns do not coincide even within one country, an epoch-wise adjustment of the measurements is not possible. Therefore, we apply a kinematic adjustment on the raw measurements resulting in a linear displacement rate at every levelling benchmark. As levelling is a relative measurement technique, the linear rates are relative to a reference point located in a presumedly stable area. The resulting linear displacement rates for the whole URG network are published by [6].

\subsection{GNSS}

The transnational cooperation project GURN (GNSS Upper Rhine Graben Network) consists of more than 80 permanently operating GNSS sites in the URG area. At present, we apply a differential processing on a network of sites using GPS observations only. For every site, daily coordinate solutions are estimated, resulting in time series for Easting, Northing and Up components. We use the CATS (Create and Analyse Time Series) software package [7] to handle jumps and periodic variations in the GNSS time series finally resulting in linear displacement rates w.r.t. ITRF2005. The vertical component of GNSS is not used in the combination, as it is a factor of 3 worse than the horizontal components and a vertical velocity field with a higher spatial resolution is available from the levelling analysis. 


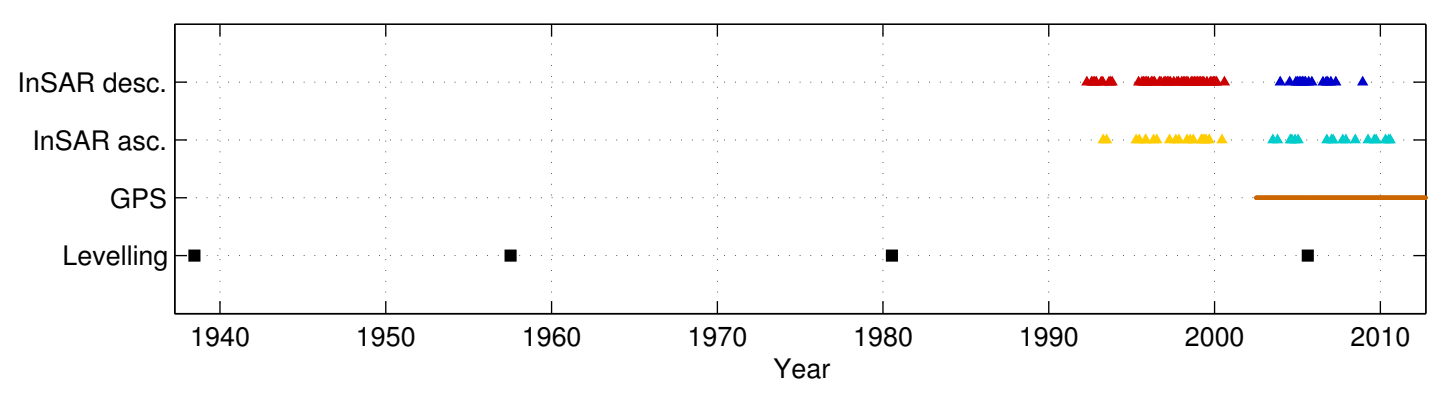

Figure 3. Representative example for the temporal distribution of the data. The colours correspond to the ones chosen in Fig. 2.

\section{COMBINATION APPROACH}

The data sets from InSAR, levelling and GNSS are inhomogeneous in space and time. When combining the displacement results of the techniques, we implicitly assume that (i) InSAR, levelling and GNSS measure the same signal, (ii) the tectonic displacements behave linearly in time and (iii) the tectonic signal is smooth in space and does not abruptly change within short distances. The latter requirement is of special importance as we interpolate the different data sets to a grid.

\subsection{Workflow of the combination}

The general workflow of our two-step combination approach is displayed in Fig. 4. As all three techniques are based on relative measurements, they depend on a reference point (levelling), a reference area (InSAR) or a reference frame (GNSS), which are located in different regions. We firstly calculate offsets between InSAR and levelling for the vertical component and between InSAR and GNSS for the horizontal component in order to shift the rates obtained from InSAR into the datum of levelling and GNSS. Therefore, the PS displacements are individually interpolated to the location of levelling benchmarks and GNSS sites. From PS velocities in ascending and descending image geometries, a mean vertical and horizontal offset between InSAR and the other two techniques is calculated and applied later in the combination step.

For the combination, we interpolate the displacement rates of all three techniques to a common grid. In order to avoid spatial extrapolation, this grid only carries values in the vicinity of existing PS points. At every valid grid point, the linear LOS velocity rates from PS-InSAR (ascending and descending) are combined with vertical velocity rates from levelling and horizontal velocity rates from GNSS resulting in a 3D velocity vector (Northing, Easting, Up). A special focus in the least squares estimation of the three displacement components is given to realistic information on the variances and covariances of the input data.

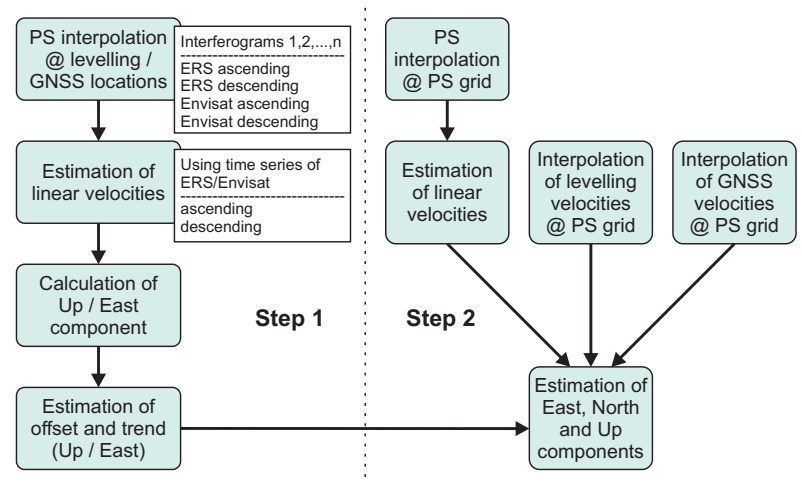

Figure 4. Workflow of the two-step combination approach. In step 1 the offset and trend between InSAR and levelling/GNSS are estimated. Step 2 mathematically combines the InSAR, levelling and GNSS estimates at the PS grid. The offset and trend estimated in step 1 are considered in the final estimation of East, North and Up components.

\subsection{Interpolation}

Spatial interpolation of the data sets is needed, as the location of the measurement points does not coincide. We use Ordinary Kriging for the interpolation of InSAR LOS displacements, vertical velocities from levelling and horizontal velocities from GNSS. The major issue within the spatial interpolation is to obtain the covariance function used for the calculation of weights of the data points at a certain prediction location. Therefore, empirical semivariograms are calculated from the data itself and a semivariogram function is fitted depending on the point distance as described by [8].

In the case of levelling and GNSS, additional information on the variances and covariances of the linear rates is available from the kinematic adjustment and the time series analysis, respectively. We include these information in the covariance model of the Kriging interpolation. The standard deviations of the resulting interpolated velocity field are low close to the data points and increase with distance.

For the interpolation of LOS displacements from InSAR located at different sets of PS points (ERS/Envisat asc/desc), the calculation of empirical semivariograms is difficult because of computational issues. In order to ob- 


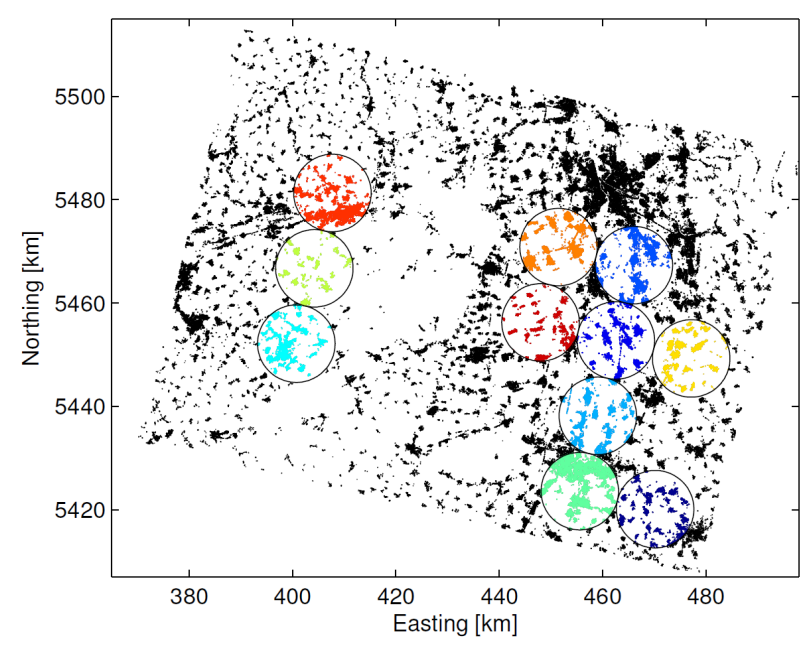

Figure 5. Areas selected for the estimation of empirical semivariograms in Envisat track 294. The colours are sorted w.r.t. the standard deviation of the LOS displacements within each area from blue (low standard deviation) to red (high standard deviation).

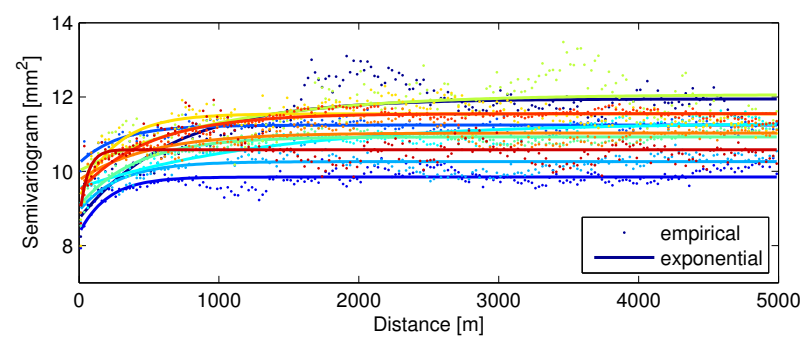

Figure 6. Empirical semivariograms and exponential models for LOS displacements in eleven weakly deforming areas of one interferogram (Envisat track 294). The different colours of the semivariograms correspond to the colours of the areas in 5.

tain a semivariogram model which reflects the signal of interest (small tectonic motion), we use a subset of areas with weakly and homogeneous deformation for the computation of the variogram statistics. The areas should contain a minimum number of PS points with a low standard deviation for all LOS displacements within one area (see Fig. 5). The corresponding empirical semivariograms and fitted semivariogram model function for the eleven areas in Fig. 5 are shown in Fig. 6. We take the median values of the model function parameters for the interpolation of PS displacements in the whole investigation area.

\subsection{Linear displacement rates from InSAR}

As a linear displacement rate gets more accurate with a longer time span, we apply the approach of [9] in order to combine the displacement time series of ERS and Envisat for both image geometries. Therefore, spatial interpolation of the PS points of every interferogram is needed, as the locations of ERS and Envisat PS points do not coincide. For the calculation of linear velocities from a combined ERS/Envisat time series, we consider both, individual accuracies of a PS point displacement in a specific interferogram as well as temporal correlations between the interferograms induced mainly by the atmospheric filtering. Besides a linear displacement (1st order polynomial function), we fit a 2 nd and a 3 rd polynomial function to the time series data. Afterwards, we test the significance of the 2nd and 3rd order polynomial coefficients against the null hypothesis of a linear movement. Most of the non-linear movements in the area of investigation could be assigned to anthropogenic deformations induced, e.g. by groundwater usage, oil extraction or mining activities which have been investigated in several case studies, e.g. by [10]. Our InSAR time series combination approach can easily be extended to data acquired from other SAR sensors, such as Sentinel-1.

\subsection{Step 1: Reference frames}

The first step of our combination approach calculates offsets and trends between the velocities mainly induced by the different reference frames used within the singletechnique analysis. For the kinematic adjustment of levelling data a reference point has to be chosen to fix the vertical datum. The resulting vertical displacement rates are relative to a reference point located in the Eastern Black Forest [6]. Within our differential GNSS analysis, we introduced ITRF2005 as reference frame. The resulting horizontal velocity field contains a ESE trend of the URG region w.r.t. to ITRF2005. We subtract the mean velocity of eight GNSS sites located in the East of the network in order to derive the relative movements of the URG area. The vertical and the horizontal velocity field are thus both relative to the Eastern part of the region. The vertical offsets calculated for the two test areas are small $(0.04 \mathrm{~mm} / \mathrm{a}$ in area 1 and $-0.02 \mathrm{~mm} / \mathrm{a}$ in area 2$)$, as the reference areas for the InSAR analyses were selected based on a priori knowledge from the levelling adjustment. The horizontal offsets of InSAR w.r.t. the GNSS velocity field are $-0.37 \mathrm{~mm} / \mathrm{a}$ and $-0.51 \mathrm{~mm} / \mathrm{a}$ in area 1 and area 2, respectively. Besides the offsets we estimate a trend, i.e. a linear ramp, reflecting residual orbital or atmospheric effects inherent to the InSAR velocities. The trends in area 1 and area 2 are $0.39 \mathrm{~mm} / \mathrm{a}$ and $0.80 \mathrm{~mm} / \mathrm{a}$ per $100 \mathrm{~km}$ for the vertical velocities and $0.07 \mathrm{~mm} / \mathrm{a}$ and $1.67 \mathrm{~mm} / \mathrm{a}$ per $100 \mathrm{~km}$ for the horizontal velocities.

\subsection{Step 2: Mathematical combination}

At every valid grid point, we apply LSA as proposed by [11] and estimate three velocity components in East, North and Up direction $\left(v_{E}, v_{N}, v_{U}\right)$ from the set of five given observations: 


$$
\left(\begin{array}{c}
V_{I, \text { asc }} \\
V_{I, \text { desc }} \\
V_{G, E} \\
V_{G, N} \\
V_{L}
\end{array}\right)=\left(\begin{array}{ccc}
S_{a s c, E} & S_{a s c, N} & S_{a s c, U} \\
S_{d e s c, E} & S_{d e s c, N} & S_{d e s c, U} \\
1 & 0 & 0 \\
0 & 1 & 0 \\
0 & 0 & 1
\end{array}\right)\left(\begin{array}{c}
v_{E} \\
v_{N} \\
v_{U}
\end{array}\right)+e
$$

$V_{I, a s c}, V_{I, \text { desc }}$ denote the linear velocities from InSAR in ascending and descending image geometry, $V_{G, E}, V_{G, N}$ the linear velocities from GNSS in East and North direction and $V_{L}$ the vertical velocities from levelling. The vectors $S_{a s c}$ and $S_{d e s c}$ contain the projection of LOS displacements to East, North and Up components using the satellites' heading and incidence angle. The covariance matrix of observations of the LSA is given by

$Q_{y y}=\left(\begin{array}{c}\sigma_{V_{I, a s c}}^{2} \\ 0 \\ 0 \\ 0 \\ 0\end{array}\right.$ 0
$\sigma_{V_{I, \text { desc }}}^{2}$
0
0
0

$$
\begin{gathered}
0 \\
0 \\
\sigma_{V_{G, E}}^{2} \\
\sigma_{V_{G, E, N}} \\
0
\end{gathered}
$$

As the standard deviations $\sigma_{V_{L}}$ and $\sigma_{V_{G}}$ increase within distance to the data points, the velocities from InSAR predominate the combined solution in areas, where no information from levelling and GNSS is available. The covariances between the horizontal components of GNSS $\sigma_{V_{G, E, N}}$ are below $\pm 2 \%$ at $90 \%$ of the GNSS sites. Neglecting the covariances has thus only small effects on the velocity estimates (below $0.006 \mathrm{~mm} / \mathrm{a}$ ).

\section{RESULTS}

We apply our combination approach to test areas in the northern and the southern URG (cf. Fig. 1), denoted as area 1 and area 2, respectively. The results for horizontal and vertical velocities are shown in Fig. 7. In both test areas the velocity field is characterised by small linear rates. The larger subsidences close to the cities of Landau and Mannheim (northern URG) are at least partly affected by anthropogenic activities, such as oil and groundwater extraction, and have already been investigated in detail [10]. In area 2 larger subsidences occur west of the city of Mulhouse where potash was extracted until 2002. As InSAR is the only technique covering the whole mining area, the interpolated velocity field of levelling and GNSS does not include the deformation in this area. Thus, some unrealistic horizontal velocities can be observed and the standard deviations shown in Fig. 8 are significantly larger compared to other regions.

The mean standard deviations of the estimated velocities are $0.20,0.24,0.10 \mathrm{~mm} / \mathrm{a}$ (East, North, Up component) in area 1 and $0.30,0.36,0.12 \mathrm{~mm} / \mathrm{a}$ in area 2 . The standard deviations of horizontal velocities are smaller close to the location of GNSS sites and increasing in regions where no information from GNSS is available, e.g., in the southeastern part of area 2. The standard deviations of vertical velocities are smaller than the horizontal ones and more homogeneously distributed, as they are well constrained by the spatially dense levelling and InSAR data.

In general, the velocity fields fit reasonably well to the geological concepts of the URG. The maximum far-field stress component is orientated $\mathrm{N} 154^{\circ} \mathrm{E}$ [12], matching the direction of the horizontal velocity vectors in the northwestern corners of both test areas. In area 1 , eastward movements of the order of $0.2 \mathrm{~mm} / \mathrm{a}$ are observed in the southern part of the graben interior, while the northern part moves towards West with a rate of approximately $0.3 \mathrm{~mm} / \mathrm{a}$. The antithetic displacement directions, together with a significant clockwise rotation of the velocity vectors in the western part, can be attributed to the change in strike of the graben from $\mathrm{N} 30^{\circ} \mathrm{E}$ to N. According to [12] the southern part in Fig. 7, top, is in a restraining bend setting while the northern part is in a releasing bend setting. The releasing bend setting is accompanied by subsidence with rates of $0.4 \mathrm{~mm} / \mathrm{a}$ and coincides with a well-known Neogene and Quarternary depocentre. In contrast, no vertical movements are observed in the restraining part of the bend, while an uplift tendency of about $0.2 \mathrm{~mm} / \mathrm{a}$ prevails along the northwestern graben shoulder. In addition, several NNW striking, active fault segments mark the transition from the uplifting, eastward moving, restraining part of the bend in the South to the subsiding, westward moving, releasing part in the North.

In area 2 an uplift of maximum $0.5 \mathrm{~mm} / \mathrm{a}$ is visible in the alpine foreland (southeast of Fig. 7, bottom), which can be related to the general uplift of the Alps. At the eastern border fault of the URG a transition from slightly positive velocities to subsidences of about $0.3 \mathrm{~mm} / \mathrm{a}$ is observed close to the city of Freiburg. A detailed case study along the levelling lines crossing the border fault in this region has already been done by [13]. Three provinces with distinct horizontal movements are observed in this test area: (i) the alpine foreland moving in East-North-East directions, (ii) the Kaiserstuhl area near Freiburg moving towards the North, and (iii) the northwestern Graben shoulder moving towards South-East. The relative movements of the latter two provinces are indicative for sinistral shearing which would be compatible with the generally accepted models of contemporary deformation of the URG. Within the graben interior, the displacement rates are generally small, while opposing velocity vectors on both graben shoulders would indicate a shortening across the graben in the central part of area 2. This observation is in contrast to the prevailing geological point of view and has not yet been finally discussed. 

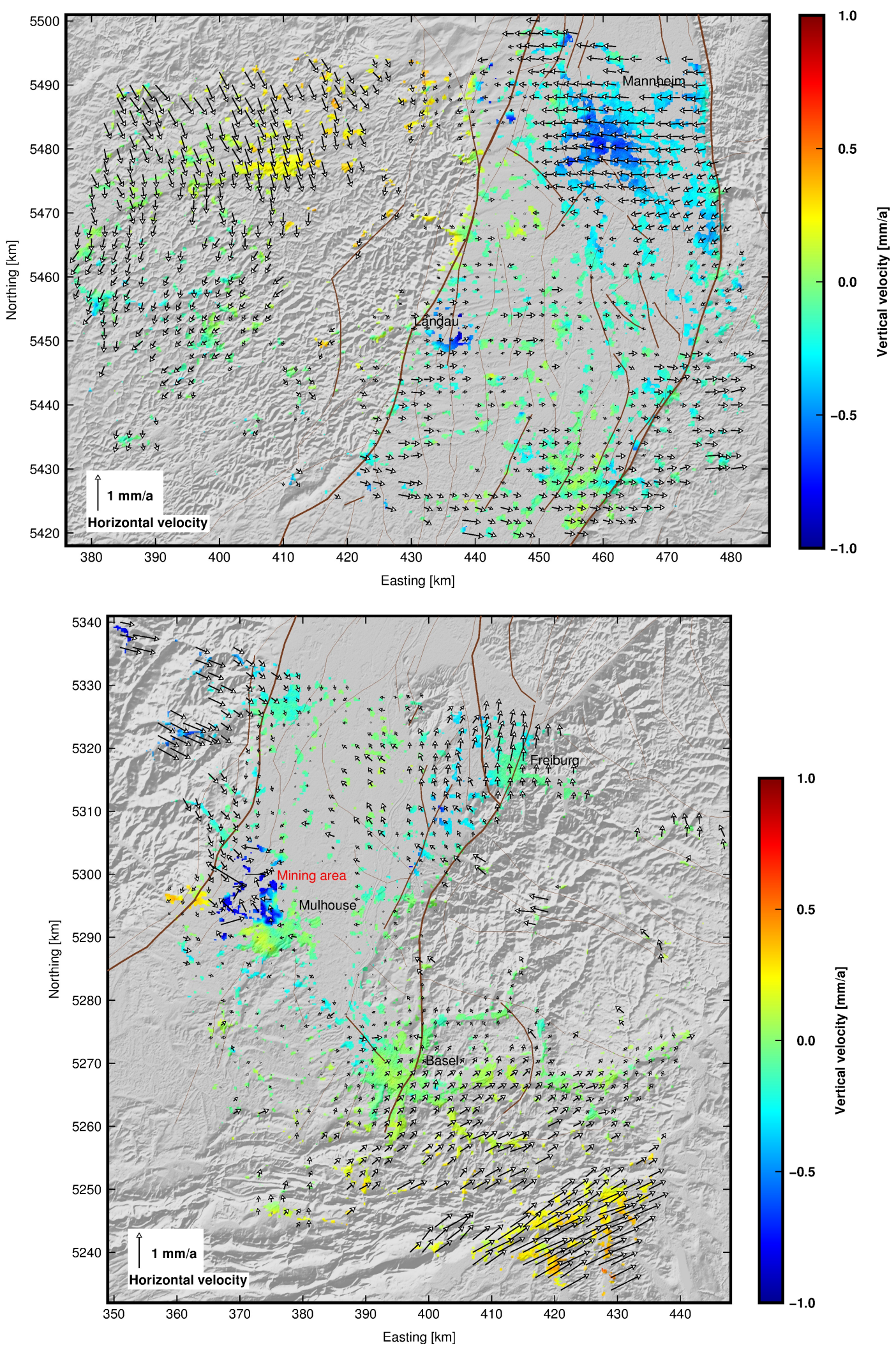

Figure 7. Final result of the combination of InSAR, levelling and GNSS: horizontal linear rates (arrows) and vertical linear rates (color-coded). Top: test area 1, bottom: test area 2. The horizontal velocity field is interpolated to a $2 \mathrm{~km}$ grid for visualisation purpose. The vertical movements are relative to a reference point in the Eastern Black Forest, the horizontal movements are relative to the mean displacement of eight sites located East of the Black Forest. Brown lines represent faults in the URG area after [3], main border faults (thick), active faults (medium thick), and other faults (thin). Grey background: shaded DEM using SRTM-3 data. 

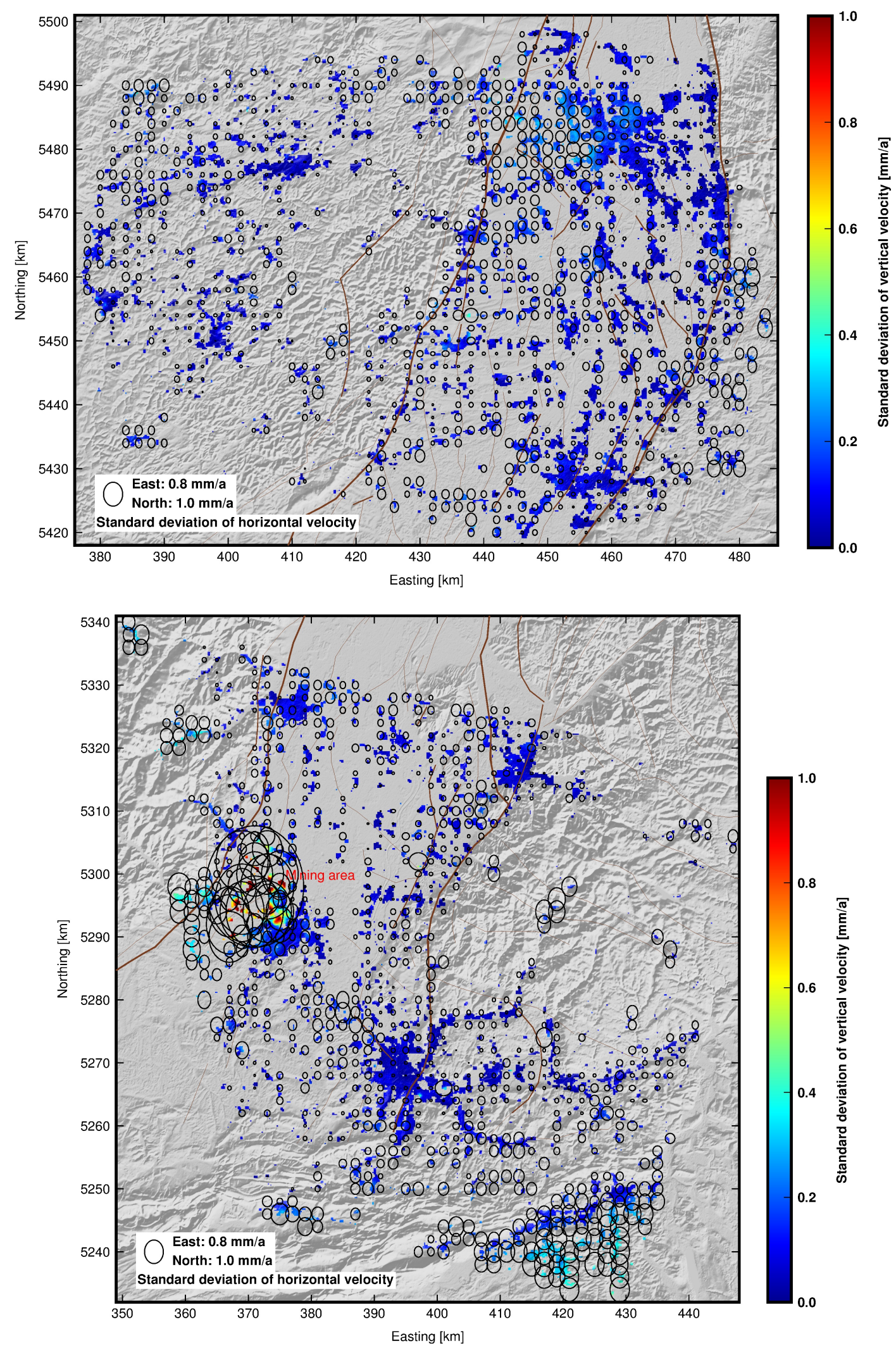

Figure 8. Standard deviation of linear rates: horizontal (ellipses) and vertical (color-coded). Top: test area 1, bottom: test area 2. Brown lines represent faults in the URG area after [3], main border faults (thick), active faults (medium thick), and other faults (thin). Grey background: shaded DEM using SRTM-3 data. 


\section{CONCLUSIONS}

We presented a consistent approach to estimate 3D surface displacements from a combination of InSAR, levelling and GNSS data. Focussing on linear displacement rates from single-technique analysis, our two-step approach accounts for the different reference frames inherent to the techniques and estimates $3 \mathrm{D}$ velocity vectors at a dense surface grid. To obtain significant velocity estimates from InSAR we combine the displacement time series of ERS and Envisat data using LSA including a realistic temporal covariance model for the observations. The combination of linear displacement rates from InSAR (LOS: ascending and descending), levelling (vertical) and GNSS (horizontal: east and west) is carried out using LSA at a surface grid containing values only close to the location of PS points. The combination approach together with the available data enables to estimate 3D displacement rates at the sub-mm/a scale. Corresponding mean standard deviations are approximately $0.3 \mathrm{~mm} / \mathrm{a}$ for the horizontal velocities and $0.1 \mathrm{~mm} / \mathrm{a}$ for the vertical velocities. Future work aims on estimating 3D velocities for the whole URG area using up to $300 \mathrm{~km}$ long stripes of SAR data together with the levelling and GNSS networks. Therefore, the handling of SAR data from only one image geometry and at overlapping areas of adjacent tracks will be further investigated.

\section{ACKNOWLEDGMENTS}

We thank our data providers for supplying GNSS and levelling data: RENAG (France), RGP (France), Teria (France), Orpheon (France), SAPOS ${ }^{\circledR}$ BadenWürttemberg (Germany), SAPOS ${ }^{\circledR}$ Rheinland-Pfalz (Germany), swisstopo (Switzerland), European Permanent Network, IGS, IGN (France), Landesamt für Geoinformation und Landmanagement (Baden-Württemberg, Germany), Landesamt für Vermessung und Geobasisinformation (Rheinland-Pfalz, Germany) and Landesamt für Kataster-, Vermessungs- und Kartenwesen (Saarland, Germany). We thank ESA for providing SAR data under the project ID 14193, TU Delft for providing orbit files and the DORIS software, as well as University of Leeds for providing the StaMPS software package. The project is funded through the German Science Foundation (DFG) under the grant HE 1433/17-2.

\section{REFERENCES}

1. P.A. Ziegler. European Cenozoic rift system. Tectonophysics, 208:91 - 111, 1992.

2. M. Meghraoui, B. Delouis, M. Ferry, D. Giardini, P. Huggenberger, I. Spottke, and M. Granet. Active Normal Faulting in the Upper Rhine Graben and Paleoseismic Identification of the 1356 Basel Earthquake. Science, 293(5537):2070-2073, 2001.
3. G. Peters. Active tectonics in the Upper Rhine Graben - Integration of paleoseismology, geomorphology and geomechanical modeling. PhD thesis, University Amsterdam, the Netherlands, 2007.

4. A. Hooper, P. Segall, and H. Zebker. Persistent scatterer interferometric synthetic aperture radar for crustal deformation analysis, with application to Volcán Alcedo, Galápagos. Journal of Geophysical Research: Solid Earth, 112(B7), 2007.

5. F.J. van Leijen. Persistent Scatterer Interferometry based on geodetic estimation theory. PhD thesis, Delft University of Technology, The Netherlands, 2014.

6. T. Fuhrmann, M. Westerhaus, K. Zippelt, and B. Heck. Vertical displacement rates in the Upper Rhine Graben area derived from precise leveling. Journal of Geodesy, 88(8):773-787, 2014.

7. S.D.P. Williams. CATS: GPS coordinate time series analysis software. GPS Solutions, 12(2):147-153, 2008.

8. E. Gringarten and C. Deutsch. Teacher's aide variogram interpretation and modeling. Mathematical Geology, 33(4):507-534, 2001.

9. M. Caro Cuenca, S.S. Esfahany, and R.F. Hanssen. A least squares approach for joining Persistent Scatterer InSAR time series acquired by different satellites. In Proc. of ESA Living Planet Symposium, Bergen, Norway, 28 June - 2 July 2010, 2010.

10. T. Fuhrmann, A. Knöpfler, M. Mayer, A. Schenk, M. Westerhaus, K. Zippelt, and B. Heck. Towards a Fusion of SAR-Interferometry, GNSS and Precise Levelling in the Upper Rhine Graben Area, Southwest Germany. In L. Ouwehand, editor, Proceedings of ESA Living Planet Symposium, number SP-722, 2013.

11. M. Caro Cuenca, R.F. Hanssen, A. Hooper, and M. Arikan. Surface Deformation of the Whole Netherlands After PSI Analysis. In Proceedings Fringe 2011 Workshop, Frascati, Italy, 19-23 September 2011, 2012.

12. T.J. Buchmann and P.T. Connolly. Contemporary kinematics of the Upper Rhine Graben: A 3D finite element approach. Global and Planetary Change, 58(1-4):287 - 309, 2007. TOPO-EUROPE: the Geoscience of Coupled Deep Earth-Surface Processes.

13. T. Fuhrmann, B. Heck, A. Knöpfler, F. Masson, M. Mayer, P. Ulrich, M. Westerhaus, and K. Zippelt. Recent surface displacements in the Upper Rhine Graben - Preliminary results from geodetic networks. Tectonophysics, 602(0):300-315, 2013. 